\title{
Exercise as Medicine for Children with Arthritis
}

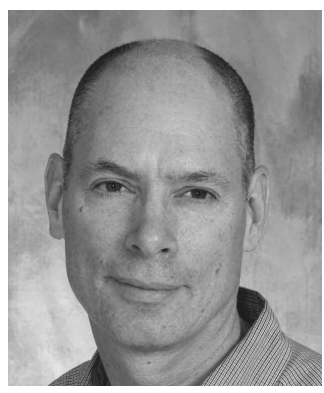

Childhood arthritis, including juvenile idiopathic arthritis $(\text { JIA })^{1}$, is a group of diseases whose face has changed over the last 3 decades. Phenomenal new treatment approaches, available widely in developed and some developing nations ${ }^{2,3}$, have turned once crippling disorders into conditions for which new challenges have emerged.

While the severe, deforming, and crippling effects of arthritis are to a large degree a thing of the past (at least in resource-rich nations), children with arthritis still face a number of challenges. Most children with JIA have ongoing pain $^{4,5}$, and many do not have the same level of social and role participation as their healthy peers.

Traditional approaches to therapy for children who have arthritis centered around strengthening and range of motion exercises targeted toward specific joints. For example, many of my arthritis patients, well into the 1990s, were admitted to a rehabilitation center for splinting, pool therapy, and individual joint exercises.

With the onset of more powerful biologic and nonbiologic disease-modifying treatments, this is now rarely necessary.

In more recent years the approach of many, including our team, is to shift the focus of therapy toward fitness exercise - an "exercise as medicine" approach. This is predicated on the knowledge that children with arthritis are less active than their peers and are in poorer physical condition ${ }^{6}$. By reversing poor physical fitness, it is possible that we can solve some of the current problems that result from childhood arthritis.

Fitness exercise is a subcategory of physical activity. As defined by Caspersen, et al, "Exercise is physical activity that is planned, structured, repetitive, and purposive in the sense that improvement or maintenance of one or more components of physical fitness is an objective" .

There is broad agreement that fitness exercise leads to many salutary health benefits. The Centers for Disease Control and Prevention (CDC) promote exercise as a way to control weight, reduce the risk of cardiovascular disease, reduce the risk for type II diabetes, reduce the risk for some cancers, improve mental health and mood, improve physical function, and improve longevity ${ }^{8}$. This has led many to embrace the idea of "Exercise as Medicine."

Exercise as medicine is a concept that has a long history9. For example, "Among the ancient Greeks, the recognition that proper amounts of physical activity are necessary for healthy living dates back to at least the 5th century B.C.... The lessons found in the 'laws of health' taught during the ancient period sound familiar to us today: to breathe fresh air, eat proper foods, drink the right beverages, take plenty of exercise, get the proper amount of sleep, and include our emotions when analyzing our overall well-being" $(C D C)^{10}$.

Currently, the exercise as medicine concept is being promoted by The American College of Sports Medicine and the American Medical Association through their nonprofit Exercise is Medicine initiative ${ }^{11}$ (www.exerciseismedicine.org). There are international branches (e.g., Exercise is Medicine Canada, exerciseismedicine.org/canada).

Further, there is empirical evidence that proper exercise may, in many situations, be as potent as traditional medicines ${ }^{12,13}$.

Exercise as medicine for childhood arthritis has been studied, but only to a limited extent ${ }^{14-23,24}$. For example, we did a randomized trial that compared aerobic fitness exercise (cardio-karate) with weight-bearing but nonaerobic exercise (qigong). We found clinically important improvements in physical function in both groups, but no significant improvement in fitness in the aerobic training group ${ }^{20}$. Similarly, a Cochrane review in 2008 concluded that while fitness exercise was safe in children with arthritis, "overall, exercise therapy did not result in significant effects on functional ability, health-related quality of life, aerobic capacity, or pain" 25 .

There may be several reasons why current studies have largely not shown important training effects. For one thing, it is very difficult, in general, to induce a training effect in younger children. Another reason, though, that our study highlighted is that there is poor adherence to training

See Measuring PA in JIA, page 1249

Personal non-commercial use only. The Journal of Rheumatology Copyright (C 2017. All rights reserved. 
programs. In our study, only a small proportion of our aerobic study group achieved an intense-enough workout often enough to have expected to see a training effect. We found that there were several barriers to exercise in our study and in children with arthritis overall ${ }^{26}$.

From this work, and other similar unpublished research, I have concluded that a more successful strategy, more successful than institution-based fitness programs, is to use behavioral change strategies to increase habitual activity in children with arthritis - and to try to achieve the important health benefits of exercise that way. One way to do this is to increase physical literacy. For those unfamiliar with the concept, according to The International Physical Literacy Association, "Physical literacy can be described as the motivation, confidence, physical competence, knowledge and understanding to value and take responsibility for engagement in physical activities for life" 27 .

However, to know whether improving habitual activity is effective in improving the health of children with arthritis, we need to be able to know whether we are improving habitual activity; i.e., we must be able to measure activity levels.

Traditionally, measurement of activity is done using either questionnaires or devices that measure some aspect of activity, such as pedometers or accelerometers; both have their challenges. While many measures of fitness are very stable (reliable), we and others have found that activity questionnaires for children are much less reliable ${ }^{28}$. Accelerometry, an objective measure of activity, has validity issues when applied to children with chronic diseases such as arthritis; this is probably because movement patterns and metabolic expenditure are affected in a variety of ways by illness ${ }^{29,30}$.

In this issue of The Journal, investigators from 3 Dutch cities studied a way of improving the validity of accelerometer measures in childhood arthritis as a substudy of the Rheumates@work study ${ }^{31}$. A major problem with accelerometers is non-wear time (i.e., time in which the accelerometer is supposed to be worn, but it is not). The investigators posited that activity diary data, in which activity levels every 15 min were recorded by their subjects, could be used to fill in the missing data that resulted from accelerometer non-wear. Not surprisingly, subjects reported more intense activity, and less rest time, in their diaries than was recorded objectively by the accelerometers. When the activity diary was used to correct the estimates of activity (presumed to be under-called by accelerometry because of periods of non-wear), the improvement at the group level was small. However, some subjects, presumably those who wore the accelerometers least often, saw big changes when the diary was used to fill in missing data.

I believe that exercise as medicine for children with arthritis holds great promise. The way to best achieve that promise remains an area of active investigation. We need accurate ways to measure activity as we study new strategies.
Armbrust, $e t a l^{31}$ have offered up one such strategy. This is an area of research well worth pursuing.

BRIAN M. FELDMAN, MD, MSc, FRCPC, Department of Pediatrics, Hospital for Sick Children, Toronto, Ontario, Canada.

Address correspondence to Dr. B.M. Feldman, 555 University Ave., Toronto, Ontario M5G 1X8, Canada. E-mail: brian.feldman@sickkids.ca

\section{REFERENCES}

1. Petty RE, Southwood TR, Baum J, Bhettay E, Glass DN, Manners $\mathrm{P}$, et al. Revision of the proposed classification criteria for juvenile idiopathic arthritis: Durban, 1997. J Rheumatol 1998;25:1991-4.

2. Ringold S, Weiss PF, Beukelman T, DeWitt EM, Ilowite NT, Kimura Y, et al; American College of Rheumatology. 2013 update of the 2011 American College of Rheumatology recommendations for the treatment of juvenile idiopathic arthritis: recommendations for the medical therapy of children with systemic juvenile idiopathic arthritis and tuberculosis screening among children receiving biologic medications. Arthritis Rheum 2013;65:2499-512.

3. Beukelman T, Patkar NM, Saag KG, Tolleson-Rinehart S, Cron RQ, DeWitt EM, et al. 2011 American College of Rheumatology recommendations for the treatment of juvenile idiopathic arthritis: initiation and safety monitoring of therapeutic agents for the treatment of arthritis and systemic features. Arthritis Care Res 2011;63:465-82.

4. Tupper SM, Rosenberg AM, Pahwa P, Stinson JN. Pain intensity variability and its relationship with quality of life in youths with juvenile idiopathic arthritis. Arthritis Care Res 2013;65:563-70.

5. Bromberg MH, Connelly M, Anthony KK, Gil KM, Schanberg LE. Self-reported pain and disease symptoms persist in juvenile idiopathic arthritis despite treatment advances: an electronic diary study. Arthritis Rheumatol 2014;66:462-9.

6. Takken T, Hemel A, van der Net J, Helders PJ. Aerobic fitness in children with juvenile idiopathic arthritis: a systematic review. J Rheumatol 2002;29:2643-7.

7. Caspersen CJ, Powell KE, Christenson GM. Physical activity, exercise, and physical fitness: definitions and distinctions for health-related research. Public Health Rep 1985;100:126-31.

8. Centers for Disease Control and Prevention. Physical activity and health. [Internet. Accessed May 1, 2017.] Available from: www.cdc.gov/physicalactivity/basics/pa-health

9. Tipton CM. The history of "Exercise Is Medicine" in ancient civilizations. Adv Physiol Educ 2014;38:109-17.

10. Centers for Disease Control and Prevention. Historical background and evolution of physical activity recommendations. [Internet. Accessed May 1, 2017.] Available from: www.cdc.gov/nccdphp/ sgr/intro2.htm

11. Wikipedia, The Free Encyclopedia. Exercise is medicine. [Internet. Accessed May 1, 2017.] Available from: wikipedia.org/w/ index.php?title=Exercise_is_Medicine\&oldid=767821654

12. Naci H, Ioannidis JP. Comparative effectiveness of exercise and drug interventions on mortality outcomes: metaepidemiological study. BMJ 2013;347:f5577.

13. Pederson BK, Saltin B. Exercise as medicine - evidence for prescribing exercise as therapy in 26 different chronic diseases. Scand J Med Sci Sports 2015;25 Suppl 3:1-72.

14. Elnaggar RK, Elshafey MA. Effects of combined resistive underwater exercises and interferential current therapy in patients with juvenile idiopathic arthritis: a randomized controlled trial. Am J Phys Med Rehabil 2016;95:96-102.

Personal non-commercial use only. The Journal of Rheumatology Copyright @ 2017. All rights reserved 
15. Baydogan SN, Tarakci E, Kasapcopur O. Effect of strengthening versus balance-proprioceptive exercises on lower extremity function in patients with juvenile idiopathic arthritis: a randomized, single-blind clinical trial. Am J Phys Med Rehabil 2015;94:417-24, quiz 425-8.

16. Doğru Apti M, Kasapçopur Ö, Mengi M, Öztürk G, Metin G. Regular aerobic training combined with range of motion exercises in juvenile idiopathic arthritis. Biomed Res Int 2014;2014:748972.

17. Tarakci E, Yeldan I, Baydogan SN, Olgar S, Kasapcopur O. Efficacy of a land-based home exercise programme for patients with juvenile idiopathic arthritis: a randomized, controlled, single-blind study. J Rehabil Med 2012;44:962-7.

18. Sandstedt E, Fasth A, Fors H, Beckung E. Bone health in children and adolescents with juvenile idiopathic arthritis and the influence of short-term physical exercise. Pediatr Phys Ther 2012;24:155-61; discussion 62 .

19. Lelieveld OT, Armbrust W, Geertzen JH, de Graaf I, van Leeuwen MA, Sauer PJ, et al. Promoting physical activity in children with juvenile idiopathic arthritis through an internet-based program: results of a pilot randomized controlled trial. Arthritis Care Res 2010;62:697-703.

20. Singh-Grewal D, Schneiderman-Walker J, Wright V, Bar-Or O, Beyene J, Selvadurai $\mathrm{H}$, et al. The effects of vigorous exercise training on physical function in children with arthritis: a randomized, controlled, single-blinded trial. Arthritis Rheum 2007;57:1202-10.

21. Singh-Grewal D, Wright V, Bar-Or O, Feldman BM. Pilot study of fitness training and exercise testing in polyarticular childhood arthritis. Arthritis Rheum 2006;55:364-72.

22. Takken T, Van Der Net J, Kuis W, Helders PJ. Aquatic fitness training for children with juvenile idiopathic arthritis. Rheumatology 2003;42:1408-14.
23. Takken T, van der Net J, Helders PJ. Do juvenile idiopathic arthritis patients benefit from an exercise program? A pilot study. Arthritis Rheum 2001;45:81-5.

24. Klepper SE. Effects of an eight-week physical conditioning program on disease signs and symptoms in children with chronic arthritis. Arthritis Care Res 1999;12:52-60.

25. Takken T, Van Brussel M, Engelbert RH, Van Der Net J, Kuis W, Helders PJ. Exercise therapy in juvenile idiopathic arthritis: a Cochrane Review. Eur J Phys Rehabil Med 2008;44:287-97.

26. Hutzal CE, Wright FV, Stephens S, Schneiderman-Walker J, Feldman BM. A qualitative study of fitness instructors' experiences leading an exercise program for children with juvenile idiopathic arthritis. Phys Occup Ther Pediatr 2009;29:409-25.

27. International Physical Literacy Association. [Internet. Accessed May 1, 2017.] Available from: www.physical-literacy.org.uk

28. Stephens S, Singh-Grewal D, Bar-Or O, Beyene J, Cameron B, Leblanc CM, et al. Reliability of exercise testing and functional activity questionnaires in children with juvenile arthritis. Arthritis Rheum 2007;57:1446-52.

29. Stephens S, Takken T, Esliger DW, Pullenayegum E, Beyene J, Tremblay M, et al. Validation of accelerometer prediction equations in children with chronic disease. Pediatr Exerc Sci 2016;28:117-32.

30. Takken T, Stephens S, Balemans A, Tremblay MS, Esliger DW, Schneiderman J, et al. Validation of the Actiheart activity monitor for measurement of activity energy expenditure in children and adolescents with chronic disease. Eur J Clin Nutr 2010; 64:1494-500.

31. Armbrust W, Bos GJ, Geertzen JH, Sauer PJ, Dijkstra PU, Lelieveld OT. Measuring physical activity in juvenile idiopathic arthritis: activity diary versus accelerometer. J Rheumatol 2017;44:1249-56.

J Rheumatol 2017;44:1103-5; doi:10.3899/jrheum.170461 